\title{
К.В. Смирнова
}

\section{ОБРАЗ МУЖЧИНЫ В МОНУМЕНТАЛЬНОЙ НЕМЕЦКОЙ ПЛАСТИКЕ 1930-1940-Х ГОДОВ}

\begin{abstract}
Монументальной скульптуре в Третьем рейхе отводилась одна из главнейших ролейэто было самое действенное звено культурной политики. Именно в пластике выразились имперский стиль и идеальный образ, отвечающий идеологии и духу диктаторского режима. Доводя скульптурный мужской образ до стадии абсолюта, мастера Имперской палаты утверждали новый образ сверхчеловека. Спокойно стоящая мужская фигура, представленная в классическом контрапосте, стала олицетворением идеального представителя нордической расьл.

Ключевые слова: Германия, скульптура, монументальная скульптура, Третий рейх.
\end{abstract}

Несмотря на характерные для первой половины XX в. радикальные обновления искусства ${ }^{1}$, немецкая скульптурная школа этого периода сохранила приверженность к фигуративному изобразительному языку. Художники поновому увидели и переосмыслили творческое наследие Аристида Майоля (1861-1944), Огюста Родена (1840-1917) и мюнхенского скульптора и теоретика Адольфа фон Хильдебрандта (1847-1921). Здесь уместно вспомнить и о явлении «творческой ретроспекции» $[1,2]$, сказавшейся в обращении к скульптуре Древнего Египта, архаике античного Рима, немецкого средневековья, и о переосмыслении этих традиций в контексте современного для того времени (период между двумя войнами, Первой и Второй мировой) художественного мышления.

Трактовка образа человека в немецкой скульптуре этого периода крайне разнообразна и неоднозначна. Дело в том, что в послевоенной Веймарской республике ситуация была сложной: голод, экономический кризис, безработица, обилие нищих и калек, изуродованных войной, политические убийства. В 1923 г. происходит знаменитый «Пивной путч» ${ }^{2}$ в одном из баров Мюнхена, когда Национал-социалистическая рабочая партия Германии (НСДАП) во главе с Адольфом Гитлером и генералом Людендорфом попыталась захватить власть в стране. Начинается сперва белый, затем коричневый террор. Нацистские идеи постепенно захватывали сознание людей, что привело в 1933 г. к утверждению режима Гитлера. Все эти события отразились и на ху-

\footnotetext{
${ }^{1}$ В начале XX в. произошли не только существенные реформы политико-социальных условий жизни людей, но и в корне изменилось сознание и мировоззрение человека нового столетия. Великий немецкий мыслитель XX в. Ницше стал тем «рычагом», идеи которого с большим энтузиазмом и азартом принялись воплощать в жизнь: утверждать новые заповеди на новых скрижалях, а также искать нового человека. Радикальные обновления коснулись всех областей жизни человека. В искусстве формальное новаторство, стремление к декоративности зачастую брали верх над натуралистичностью и внутренним содержанием образа. Художники интерпретировали натуру через призму внутреннего переживания, таким образом, каждое произведение становилось некой проекцией внутреннего Я творца. Вне зависимости от какой-либо конкретной живописной манеры внешний образ начинал приноситься в жертву внутреннему миру и натуралистическому подобию.

${ }^{2}$ Известный также как «путч Гитлера и Людендорфа».
} 
дожественной жизни страны. В Германии появилось два «лагеря» - мастера, не вступившие в гитлеровскую партию, так называемые художники Сопротивления [3], и мастера официальные, вступившие в НСДАП и вошедшие в состав Имперской палаты искусств. Обращаясь к языку пластических форм, эти мастера по-разному трактовали образ человека - как с точки зрения формы, так и с позиций содержания. Древнеегипетские, архаичные и средневековые реминисценции характерны для мастеров, оппозиционных Рейху (Эрнст Барлах, Кете Кольвиц, Фриц Кремер и др.). Представители Имперской палаты искусств (Арнольд Брекер, Йозеф Торак, Георг Кольбе и др.), напротив, обращались к образцам античной пластики, которые отвечали размаху идей Гитлера.

Монументальной скульптуре в Третьем рейхе отводилась одна из главнейших ролей - это было самое действенное звено культурной политики [3]. Демонстрация ариософской мифологемы проявляла себя как стремление к власти нордического совершенства и красоты над дегенеративными неарийскими народами (у последних подчеркивалось уродство как физическое, так и нравственное, интеллектуальное, духовное). Гитлер прекрасно знал способность искусства воздействовать на души людей и преображать их сознание, манипулировать им [Там же. С. 43-49]. Таким образом, адресованная массовому зрителю, монументальная скульптура становилась главным «оружием» в имперской культурной политике ${ }^{1}$. Йозеф Геббельс в своем ежегодном выступлении в конгрессе 26 ноября 1937 г. заявил, что «ныне немецкое искусство становится компасом для всей нации» [Там же. С. 191-192]. Вторая и третья задачи заключались в том, чтобы продемонстрировать миру грандиозную силу и мощь немецкой нации и сформировать культурный эталон истинного арийца (духовный, интеллектуальный, телесный) [Там же. С. 186-195].

Арнольд Брекер (1900-1991) и Йозеф Торак (1889-1952) удостоились права называться «бессмертными» по специальному распоряжению Геббельса [4. С. 207] и являлись главными скульпторами Рейха. В 1937 г. они оба получили звания профессоров и стали возглавлять скульптурные классы: Торак в Академии Мюнхена, Брекер - в Берлинской высшей школе изобразительных искусств. Интересно, что Георг Кольбе (1877-1947), входивший в состав Имперской палаты искусств, ныне признан историками искусства и считается фигурой, чье творчество вписывается в общий контекст развития эволюции скульптуры XX в. [5]. На Брекере и Тораке до сих пор висит клеймо официальных творцов Рейха [6].

Арнольд Брекер - «самый известный скульптор нацистской Германии» [6]. Биографические детали жизни художника, его путь к вершине гитлеровского «Олимпа», достаточно подробно описывает Ю.П. Маркин в своих двух фундаментальных трудах «Немецкая скульптура 1900-1950-х годов» [1] и «Искусство Третьего рейха» [6], а также И.Д. Чечот в двух сборниках статей «Арно Брекер в искусстве XX века» [7] и «От Брекера до Бекмана» [8]. Отметим лишь, что с середины 1920-х гг. Брекер пребывал в Париже, где общался с крупными мастерами XX столетия, среди которых были Аристид Майоль (1861-1944) и Эмиль Антуан Бурдель (1861-1929). Он был в приятельских

\footnotetext{
${ }^{1}$ Статуи колоссальных размеров оформляли партийные съезды, новые архитектурные сооружения Рейха, улицы, парки и автобаны.
} 
отношениях с такими знаковыми персонажами эпохи, как Жан Кокто, Робер Делоне и Ман Рэй. В 1932 г. мастер выиграл в конкурсной борьбе право на длительную стажировку в Риме (от прусского Министерства культуры приз Виллы Массимо), где имел возможность учиться на оригинальных античных образцах (а не на слепках, созданных в академиях художеств). Другими словами, Арно Брекер был отлично подготовлен как ремесленник и знаток истории искусства, что дало ему в своем творчестве возможность раскованно и вольно импровизировать в духе великих мастеров прошлого.

Ярким примером такого откровенного цитирования можно назвать персонификацию Арнольда Брекера «Готовность» (1939). Художник создает реплику статуи Микеланджело «Давид» (1501-1504, мрамор, высота 5,17 м, Академия, Флоренция). И в том и в другом примере перед нами стоят обнаженные мужчины, сосредоточенные на предстоящей схватке. Юноши внешне спокойны, но ощущается их внутренний динамизм - мышцы напряжены, брови грозно сдвинуты, а свободная поза героев - классический пример контрапоста - подготавливает смертоносное движение. Брекер подчеркивает лишь внешнее «сходство» персонажей - преемственность арийской расы и великой античной цивилизации. Художник импровизировал в духе итальянского мастера, он как бы существовал в заданном Микеланджело потоке общих пластических форм и ощущений, наделяя при этом их совсем не гуманистическим содержанием.

Мужской образ, созданный немецким ваятелем, трактован грубо и агрессивно. Перед нами арийский «Зикфрид» ${ }^{2}-$ борец за чистоту крови и расы. Юноша готов ринуться в бой, меч в его руках наготове, взор жесткий и воинственный. Тщательная моделировка камня, проработка всех объемов и деталей человеческой фигуры, едва ли не графическое изображение мышц гиперболизируют законченный и одухотворенный образ микеланджеловского Давида. Натуралистическая лепка в трактовке Брекера получила довлеющую декоративную особенность. Перед нам словно возникает арийский Олимп, с вершины которого «священный бог немецкой нации» призывает к небезызвестным постулатам Национал-социалистической партии Германии.

«Партия» и «Вермахт» (обе 1939) - две монументальные скульптурные персонификации, украшавшие вход в Рейхсканцелярию. Квазиантичные атлеты с мечом («Вермахт») и факелом («Партия») в руках выполнены обостренно жестко. Стоящие в несколько надуманной, демонстративнодекоративной позе, эти мужчины-боги являют собой протокольновыверенную иконографию сврехчеловека: колоссальный рост, широкие плечи и узкие бедра, жесткий взгляд, сдвинутые брови с подчеркнутыми надбровными дугами и заметный, несколько выпученный вперед подбородок.

Рельефы Арно Брекера не менее остры и агрессивны. Следует назвать «Укрощающие коня» (1940), «Возмездие» (1940) и «Мститель» (1941). Жесткая графическая проработка объемов, характерная для скульптур Брекера, в рельефах выступает наиболее ярко, создавая иллюзию приближения изображения к зрителю. Моделируя форму на античный манер, Брекер делал упор

\footnotetext{
${ }^{1}$ Скульптура «Готовность» (1939) должна была украсить Почетную трибуну на Поле Цеппелина в Нюрнберге в 1939 г.

2 Зикфрид - герой-драконоборец, один из важнейших героев германо-скандинавской мифологии и эпоса, герой «Песни о Нибелунгах».
} 
на исходной прасвязи со Священной Римской империей, наследником которой Гитлер провозгласил немецкий народ. По этой причине знакомый многим образ античного героя выдавался за демиурговый в искусстве Рейха, естественно, в контексте нацистской идеологии.

Подобного рода произведения идеально «впитывались» зомбированным общественным сознанием. Именно поэтому все созданные Арнольдом Брекером образы воспринимались как орудие массового гипноза, активно воспроизводились на почтовых открытках, в газетах и рекламах. Важно отметить, что большинство монументальных работ Брекера было сознательно уничтожено союзниками весной - летом 1945 г.

Йозеф Торак - не менее значительный скульптор Третьего рейха. Он, как и Брекер, стал свидетелем гибели большинства своих работ в 1945 г. Австриец по происхождению, Йозеф Торак сумел обратить на себя внимание лишь в 47 лет во время ХІ Олимпиады [1. С. 265-270].

Наверное, одни из самых известных произведений Йозефа Торака - это скульптурные группы «Товарищество» (1937) и «Семья» (1937), установленные по сторонам главного входа в Немецкий павильон на Всемирной выставке 1937 г. в Париже [Там же. С. 82-84]. ЭКСПО-37 ознаменовалась соперничеством двух молодых свехдержав - СССР и Германии. Архитектура и скульптурное убранство павильонов известным образом отражали это противостояние. Немецкий павильон, выполненный главным архитектором Рейха Альбером Шпеером, располагался напротив советского, спроектированного Борисом Иофаном. Последний стал своеобразным постаментом для монументальной скульптурной группы Веры Мухиной «Рабочий и колхозница» (1937), выполненной из нержавеющей стали. Германия «отвечала» Союзу двумя 5-метровыми бронзовыми композициями Йозефа Торака. Скульптурная группа «Товарищество» наиболее показательна из них. Идея единства - единства немецкой, арийской нации, воплощена в образе двух сверхмускулистых мужчин, держащих друг друга за руки. Тогда как у Мухиной идея единства рабочего класса выражалась фигуративной группой из мужчины и женщины. Грубая, нарочито брутальная пластика формы Торака подчеркивала агрессивность скульптурного диалога между композициями двух стран. Замкнутая статика «Товарищества» противопоставлялась динамике порыва «Рабочего и колхозницы», создавая ощущение нерушимой крепостной стены. «Товарищество» Торака стало синонимом грубой физической силы, пугающей и устрашающей своей неколебимой решительностью. Советский павильон, в свою очередь, продемонстрировал силу духа народа.

Автор в данной статье не ставит перед собой задачу сопоставить или противопоставить тоталитарное искусство двух вышеупомянутых сверхдержав. В контексте заявленной в заглавии проблемы данное сравнение призвано подчеркнуть особенность пластики Йозефа Торака по отношению к скульптурным композициям Арнольда Брекера. Арийские персонификации в творчестве Брекера уподоблялись богам нацистского Олимпа, они аристократичны и возвышенны. У Торака, напротив, мы наблюдаем скорее гипермускулистых титанов, почти карикатурных и грубых по содержанию. Как справедливо отметил Ю. Маркин, «подобная брутальная «иконография» адресовалась вкусам не партийной элиты (для этого существовал Брекер), но 
простых филистеров и штурмовиков, уважающих только грубую силу и способных в своем инстинкте скорее разрушать, чем строить» [1. С. 158].

Парадоксальная карикатурность пластического языка грамотно воплощена в модели «Памятника Труду» (1938-1944), который предполагалось установить близ Зальцбурга, на развилке имперского автобана. Торак использовал смелую метафору - перед нами четыре титана усиленно пытаются поднять огромный валун на вершину условной горы. Трактуя имперский труд через известный фразеологизм («Сизифов труд»), Торак сильно рисковал. Важно отметить, что данная композиция должна была достигать 17 м в высоту, в силу чего дерзость художественного намека обретала колоссальное звучание. Как это не удивительно, но дерзновенный творческий акт Торака был принят и утвержден комиссией Рейха.

Интересные стилизации под искусство эпохи Ренессанса продемонстрированы Йозефом Тораком в двух конных образах - «Меченосец» и «Знаменосец» (обе - уменьшенные модели, бронза, 1941), которыми предполагалось оформить центральный вход на Немецкий стадион, входивший в архитектурный комплекс Партайтага в Нюрнберге (1934, проект А. Шпеера). Чеканные и традиционно оцепенелые титаны Торака созданы по мотивам знаменитых конных статуй итальянских кондотьеров. Вспоминается, например, бронзовая конная статуя кондотьера Венецианской республики Гаттамелета (бронза, 1447-1453 гг., Площадь дель Санто, Падуя, Италия), созданная Данателло. Однако, в отличие от утонченного и изящного искусства Ренессанса, арийские персонификации художника лишены деталей, они оригинальным образом схематизированы, естественно, в рамках возможностей, допускаемых в нацистской пластике, и максимально насыщены архитектоникой.

Рельефные композиции мастера не менее выразительны и выдержаны в узнаваемых пластических моделировках: графическая проработка всех объемов человеческого тела, гипертрофированная мускулатура, крупный нос, тяжелый лоб, крепко сжатые губы и жесткий взгляд, с подчеркнуто выделенными и несколько нахмуренными надбровными дугами.

Выделим две работы художника - «Рыбная ловля» (1935-1938) и «Тяжелая работа» (1935-1938). Агрессивно-экспрессивные двухфигурные сцены труда обостренно-графично проработаны немецким мастером. Мощная, могучая человеческая плоть, мужская, изображена Тораком артистически грамотно. Титаны-строители и титаны-крестьяне (рыбаки) демонстрируют одну только физическую силу, которая ставится мастерами Рейха во главу «пирамиды добродетелей» истинного арийца. Эксцентричные позы и жесты усиливают общий динамизм рельефов, а сильно выступающие к зрителю объемы придают сценам сюрреалистический характер.

В канун Второй мировой войны Торак, работающий в Баварии, перестал вписываться в темпы «эволюционного развития» Третьего рейха. Мастер выделялся из общей массы скульпторов Имперской палаты искусств, по духу близких Брекеру. Адольф Вампер, Пауль Брониш, Фриц Климш и другие художники Рейха выглядят не оригинальными, работы их кажутся чрезмерно слащавыми и, как сегодня сказали бы, «попсовыми». Выражая пафос и идею через формы нагого тела в духе великого Микеланджело, большинство авторов Имперской палаты были вторичны, искусство их лишено жизненной силы и внутренней энергии. Пытаясь импровизировать, как Брекер, авторы 
слишком очевидно эксплуатировали шаблонные гипсовые копии римских статуй, выполненных с греческих оригиналов, какие до сих пор стоят в любой академии художеств.

На этом однообразном и скучном фоне выделяется Вилли Меллер. В своем «Факелоносце» (1938, стела для Орденбурга Фогельзанг в Айфеле) художник по-тораковски показал мускулатуру арийского героя, используя грубую и графичную пластику формы, и по-брекеровски создал образ если не бога, то как минимум полубога. Мужчина гордо и воинственно стоит на условном Олимпе, победоносно держа в одной руке факел, а другую руку яростно сжимая в кулак.

Доводя скульптурный мужской образ до стадии абсолюта, мастера Имперской палаты утверждали новый образ сверхчеловека. Героями их композиций становились «отшлифованные фантомы мифического арийца» [1. C. 155]. Спокойно стоящая мужская фигура, представленная в классическом контрапосте, стала олицетворением идеального представителя нордической расы. За внешней тишиной и нарочитой статичностью образа скрывалась внутренняя экспрессия, побуждающая желание идти в атаку. Именно в пластике выразились имперский стиль и идеальный образ, отвечающий идеологии и духу диктаторского режима. Мастера сознательно исключали индивидуализацию образа, но выявляли типичные немецкие мужские добродетели, добавляя к ним символико-знаковые нацистские атрибуты (факел, венок, оружие). Физическая сила преподносилась как одна из основных добродетелей арийской расы.

Что касается женского образа в скульптуре Третьего рейха, то он выглядит весьма однообразно, в отличие от живописных аналогов. Мастера Имперской палаты искусств крайне редко обращаются к образу Матери-Родины, поскольку на первом месте стоял образ сверхчеловека, Героя (мужчины) в иерархии нацистских символов. Крестьянская тематика практически не встречается, в силу чего женщина в скульптуре Третьего рейха - это нагая «Гея» ${ }^{1}$, естественно трактованная в духе национал-социалистической идеологии.

\section{Литература}

1. Маркин Ю.П. Немецкая скульптура 1900-1950-х годов. М. : Галарт, 2011. 450 с.

2. Искусство, которое не покорилось. Немецкие художники в период фашизма. 1933-1945 / сост. и пер. С.Д. Комаров. М. : Искусство, 1972. 344 с.

3. Моссе Дж. Нацизм и культура. Идеология и культура национал-социализма / пер. с англ. Ю.Д. Чупрова. М. : ЗАО Центрполиграф, 2003. 446 с.

4. Голомшток И.Н. Тоталитарное искусство. М. : Галарт, 1994. 296 с.

5. Hinz B. Art of the Third Reich. Oxford : Random House USA Inc, 1979. P. 305.

6. Маркин Ю.П. Искусство Третьего рейха. М. : РИП-холдинг, 2011. 383 с.

7. Чечот И.Д. Арно Брекер в искусстве ХХ века [сб. ст.] / сост. И.Д. Чечот и А.И. Чечот. СПб. : Сеанс, 2013. 500 c.

8. Чечот И.Д. От Бекмана до Брекера. Статьи и фрагменты. СПб.: Сеанс, 2016. 626 с.

Ksenia V. Smirnova, Saint-Petersburg State University of Culture (Saint-Petersburg, Russian Federation).

E-mail: ksenia-makarenko1990@yandex.ru

Vestnik Tomskogo gosudarstvennogo universiteta. Kul'turologiya i iskusstvovedeniye - Tomsk State University Journal of Cultural Studies and Art History, 2019, 33, pp. 200-206.

\footnotetext{
${ }^{1}$ Гея - древнегреческая богиня земли.
} 
DOI: $10.17223 / 22220836 / 33 / 17$

THE IMAGE OF A MAN IN A MONUMENTAL GERMAN PLASTIC OF 1930-1940-IES.

Keywords: Germany; sculpture; monumental sculpture; the Third Reich.

Despite the characteristic for the first half of the twentieth century radical renewal of art, sculpted by the German school of this period has maintained a commitment to the figurative visual language. Monumental sculpture in the Third Reich was assigned to one of the main role that was the most effective link of the cultural policy. Imperial style and ideal image were signified in the plastic. This style was corresponding to the ideology and spirit of the dictatorial regime. Demonstration ariosophy myths manifests itself as the desire for power Aryan perfection and beauty on a degenerative non-Aryan peoples. Hitler was well aware of the ability of art to influence the souls of men and to transform their consciousness, to manipulate him. Thus, addressed to the mass audience, the monumental sculpture has become the main "weapon" in Imperial cultural politics. The second and third task was to demonstrate to the world the enormous power of the German nation and to create the cultural standard of the true Aryan (spiritual, intellectual, physical). Bringing a sculptural male figure to the stage of the absolute, masters of the Imperial chamber meanwhile were forming a new image of Superman. A Peacefully standing male figure in a classical opposite, was the epitome of a perfect representative of the Nordic race.

\section{References}

1. Markin, Yu.P. (2011) Nemetskaya skul'ptura 1900-1950-kh godov [German sculpture of the 1900-1950s]. Moscow: Galart.

2. Komarov, S.D. (ed.) (1972) Iskusstvo, kotoroe ne pokorilos'. Nemetskie khudozhniki v period fashizma. 1933-1945 [Art that did not submit. German artists during Fascism. 1933-1945]. Moscow: Iskusstvo.

3. Mosse, J. (2003) Natsizm i kul'tura. Ideologiya i kul'tura natsional-sotsializma [Nazism and culture. The ideology and culture of National Socialism]. Translated from English by Yu. D. Chuprov. Moscow: ZAO Tsentrpoligraf.

4. Golomshtok, I.N. (1994) Totalitarnoe iskusstvo [Totalitarian Art]. Moscow: Galart.

5. Hinz, B. (1979) Art of the Third Reich. Oxford: Random House USA Inc. kholding.

6. Markin, Yu.P. (2011) Iskusstvo Tret'ego Reykha [Art of the Third Reich]. Moscow: RIP-

7. Chechot, I.D. (2013) Arno Breker v iskusstve XX veka [Arnaud Brecker in the art of the 20th century]. St. Petersburg: Seans.

8. Chechot, I.D. (2016) Ot Bekmana do Brekera. Stat'i i fragment [From Beckman to Brecker. Articles and fragments]. St. Petersburg: Seans. 